\title{
Cry1F resistance among lepidopteran pests: A model for improved resistance management?
}

Ana M. Vélez * , NeethaNanothVellichirammal, Juan Luis Jurat-Fuentes ${ }^{2}$, and Blair D. Siegfried ${ }^{3}$

1 University of Nebraska-Lincoln, Department of Entomology, 103 Entomology Hall, Lincoln NE 68583-0816, United States.

2 University of Tennessee, Department of Entomology and Plant Pathology, Plant Biotechnology Building, Knoxville, TN 37919, United States. University of Florida, Entomology and Nematology Department, Charles Steinmetz Hall, PO Box 110620, Gainesville, FL 32611-0620, United States.

* Corresponding author: Ana M. Vélez, University of Nebraska-Lincoln, Department of Entomology, 103 Entomology Hall, Lincoln, NE 68583-0816, United States. Voice: +1 402-471-8694; Fax: +1 402-472-4687 E-mail address: avelezarango2@unl.edu 


\begin{abstract}
The CrylFa protein from the bacteriumBacillus thuringiensis $(\mathrm{Bt})$ is known for its potential to control lepidopteran pests, especially through transgenic expression in maize and cotton. The maize event TC1507 expressing the cry1Fatoxin gene became commercially available in the United States in 2003 for the management of key lepidopteran pests including the European corn borer, Ostrinia nubilalis, and the fall armyworm, Spodoptera frugiperda. A high-dose/refuge strategy has been widely adopted to delay evolution of resistance to event TC1507 and other transgenic Bt crops. Efficacy of this strategy depends on the crops expressing a high dose of the Bt toxin to targeted pestsand adjacent refuges of non-Bt host plants serving as a source of abundant susceptible insects. While this strategy has proved effective in delaying $O$. nubilalis resistance, field-evolved resistance to event TC1507 has been reported in S. frugiperda populations in Puerto Rico and the southeastern United States. This paper examinesavailable information on resistance to Cry1Fa in O. nubilalis and S. frugiperda and discusses how this information identifies opportunities to refine resistance management recommendations for Bt maize.
\end{abstract}

\title{
Introduction
}

The Cry1Fa protein from Bacillus thuringiensis subsp. aizawaiwas first described by Chambers et al. [1] as active against a subset of lepidopteran insects, including larvae of the European corn borer (Ostrinia nubilalis Hübner) and the beet armyworm (Spodoptera exigua Hübner). As with other insecticidal Cry proteins, the Cry1Fa mode of action involves recognition of binding sites on the midgut brush border membrane and formation of toxin pores that lead to osmotic cell death, compromising the integrity of the midgut epithelial barrier and allowing bacteria to reach the hemocoel and cause septicemia, which ultimately kills the insect host [2]. Since its discovery, the Cry $1 \mathrm{Fa}$ toxin has become widely recognized for its potential to control lepidopteran pests when produced in transgenic crop plants such as maize and cotton.

Insect-resistant transgenic maize event TC1507 expressing the cry1Fa toxin gene was commercialized as Herculex I. The technology was jointly developed by Pioneer Hi-Bred International, Inc. (DuPont Pioneer) and Dow AgroSciences LLC. As with other Bt events targeting lepidopteran pests of maize, TC1507 was developed to provide growers a simple and highly effective tool to control certain key lepidopteran larval pests[]ㅡ. The Cry1Fa concentration 
in TC1507 maize has been shown to vary among tissue types [4], but in general it is considered to express Cry1Fa at high enough concentrations to kill most susceptible target pest species. Based on laboratory studies of insect resistance to Bt toxins [5] , resistance to TC1507 and other Bt maize events producing a high dose ( 25 times the $\mathrm{LC}_{99}$ ) of a single $\mathrm{Bt}$ toxinwas expected to be monogenic, recessive and autosomal. Based on these assumptions, insect resistance management (IRM) plans for TC1507 relied on the high-dose/refuge strategy[6,7]. According to this strategyit is assumed that TC1507 expresses a high dose of the toxin that will kill at least $99 \%$ of susceptible insects in the field [6]. Thenon-Bt refuge is intended to produce an abundance of susceptible homozygous insects that would mate with the few resistant homozygous insects emerging from $\mathrm{Bt}$ maize fields, thereby producing susceptible heterozygotes that would be controlled by the Bt maize plants (Box 1) [5, $\underline{8}]$.In the case of $O$. nubilalis, it appears likely that the initial assumptions of the high-dose/refuge strategy have been met, as there has not been a detectable change in susceptibility to Cry1Fa maize in over 10 years of commercial availability [9] in the United States. This lack of fieldresistance is noteworthy because resistance in $O$. nubilalis can be readily selected underlaboratory conditions [10] and the resistance alleles can be detected in field populations [9]. In contrast, there is growing evidence from diverse geographies for resistance to Cry1Fa maize inS. frugiperda, which is an important maize pest in much of Latin America [11, $\underline{12}]$. Development of resistance to TC1507 may have been predicted considering evidence that TC1507 does not meet the assumption of high dose for $S$. frugiperda[13]. The differences between $O$. nubilalis and $S$. frugiperda in their propensity to evolve resistance, and ourunderstanding of resistance in the two species suggest that there are opportunities to refine IRM recommendations for Bt maize. In the following sections we will explore the various factors that have been identified in both species that may influence future resistancemanagementrecommendations.

\section{Resistance Evolution in Target Pest Species}

The high-dose/refuge strategy has been widely adopted to manage resistance evolution for transgenic crops expressing Bt toxins [7]. The most direct way to test and validate the high-dose model is to characterize resistant insect strains [14]. Generally, laboratory-selected strains are used to describe the potential for evolution of resistance in the field [15].However, in instances were field resistance has been reported, resistance characterization is fundamental to understand the factors influencing the evolution of resistance [16] and potential remediation strategies. Instances 
of field-evolved resistance suggest that certain assumptions of the high-dose refuge IRM strategy have not been met. The following descriptions of Cry1Fa resistance in $O$. nubilalis and $S$. frugiperda provide important examples of how resistance can be delayed when assumptions of the high-dose/refuge strategy are met and the consequences when they are not fulfilled as in the case of S. frugiperda.

\section{Laboratory Resistance in $O$. nubilalis}

A laboratory colony of $O$. nubilalis obtained from field collections throughout the central United States Corn Belt in 1996 was selected in the laboratory for resistance to Cry1Fa by exposure to surface treatedartificial diet. The selected strain developed more than 3,000-fold resistance after 35 generations of selection and survived when feeding on maize plants expressing Cry1Fa[10]. The inheritance of resistance in this strain was evaluated using concentration-response bioassays of reciprocal and parental crosses and was characterized as autosomal and recessive. Furthermore, bioassays of the backcross of the $\mathrm{F}_{1}$ generation with the Cry $1 \mathrm{~F}$ resistant strain suggested that resistance was conferred by a singlelocus or a set of tightly linked loci [15]. Additional experiments performed on Cry1Fa maize hybrids showed that resistant larvae readily survived on reproductive-stage but not on vegetative-stageTC1507 maize tissue, and that survival of heterozygoteson TC1507 was not significant. The results from this study provided the first evidence that if the assumptions of the high-dose/refuge strategy are fulfilled, thisapproach is appropriate to delay Cry1Fa resistance evolution in O. nubilalis [15]. This observation is supported by the fact that $O$. nubilalis populations have remained susceptible to Cry1Fa maize 13 years after the first commercial release[9]. Additional experiments evaluating cross-resistance in the resistant O. nubilalis strain indicated susceptibility to Cry1 Ab and Cry9C, and showed only low levels of cross-resistance ( $\sim 7$ fold) to Cry1 Ac. This cross-resistance phenotype suggested that resistance involvedalterations of binding sites shared by Cry1 Ac and Cry1Fa [17],although difference in Cry1Fa binding could not be confirmed experimentally [18]. Weak recessive fitness costs were associated with resistance in this strain [19], which would further contribute to delaying resistance in the high-dose/refuge strategy [20]. These datasuggested that maize hybrids expressing Cry1 $\mathrm{Ab}$ and Cry1Fa were likely to be compatible for resistance management inO. nubilalis [10], which has become an important component of current pyramided events for O. nubilalis control. 


\section{Field Resistance in S. frugiperda}

Maize hybrids expressing the Cry1Fa protein were the first Bt event to demonstrate satisfactory $S$. frugiperda control $[\underline{3}, \underline{21}]$. Although Cry1Fa maize hybrids were commercialized in the United States in 2003, in Puerto Rico they had been grown for hybrid development, parental seed production, and efficacy trials since 1998 [22]. In 2006, unexpected damage to TC1507 maize was reported in Puerto Rico and Cry1Fa resistance in S. frugiperda was subsequently documented $[\underline{23}, \underline{24}$ ].Storer et al. [23] and Blanco et al. [25] confirmed that field failures in Puerto Rico were associated with a high-level of resistance to the Cry1Fa protein, ranging from 1,000 to 26,000-fold depending on whether mortality or growth inhibition were tested. Resistance to Cry1Fa in $S$. frugiperda represented the first case of resistance leading to withdrawal of a Bt product from the market $[\underline{13}, \underline{16}]$. In Brazil, event TC1507 was introduced in the 2009/2010 season, and reports of economic damage and field evolved resistance emerged after a couple of years [11].The inheritance of Cry $1 F$ a resistance in S. frugiperda populations originated from Puerto Rico and Brazilwas characterized as autosomal, highly recessive $[\underline{11}, \underline{16}, \underline{23}, \underline{26}, \underline{27}]$, and monogenic $[\underline{11}, \underline{16}, \underline{27}]$. However, experiments with TC1507 maize plants and resistant $S$. frugiperda from Brazil suggested incomplete recessive resistance [28]. A more detailed report of the current $S$. frugiperda situation in Latin America is provided in the Blanco et al. manuscript in this special issue.

Cross-resistance tests indicated that Cry1Fa-resistant $S$. frugiperda larvae exhibitedresistancetoCry1A toxins, although at much lower levelsthanresistance observed for Cry1Fa[16, 23, 29, $\underline{30}]$.However, while high levels of cross-resistance to Cry1Aa were observed in resistant populations from Brazil [30],populations from Puerto Rico showed no cross-resistance against Cry1 Aa, Cry1Ba orCry2Aa, although inherent $S$. frugiperda susceptibility to these toxins was low [16]. This discrepancy between resistant strains from Puerto Rico and Brazil may represent the effect of genetic variability among $S$. frugiperda populations from diverse geographies [31].Furthermore, no cross-resistance was detected in populations from Puerto Rico tothe Vip3Aa protein[16]. Cross-resistance to commercial Bt pesticides XenTari WG and DiPel ES (Valent Biosciences, Libertyville, IL) was also evaluated in a strain from Puerto Rico; results indicated no differences in susceptibility compared to a susceptiblestrain [29]. Resistance in this strain has been found to involve reduced Cry1Fa toxin binding to a site shared with Cry $1 \mathrm{Ab}$ and Cry1Ac toxins [26]. 
Multiple factors, most of them shared between Puerto Rico and Brazil,are thought to have contributed to the rapid evolution of resistance to Cry1Fa in $S$. frugiperda populations in these geographies: (1) an isolated ecosystem, in the case of Puerto Rico, that restricts movement and enables local selection; (2) a tropical environment thatallows for year-round cultivation of maize with multiple insect generations exposed to selection pressure in a single growing year; (4) long history of use of formulated Bt insecticides; (5) the affected Bt maize lines not being adapted to tropical conditions; and (6) a severe drought in 2006in Puerto Rico that forced S. frugiperda populations to move to irrigated Cry1Fa maize causing intense selection pressure. In addition to these conditions, Cry1Fa maize has been shown not to represent a high dose crop for S. frugiperda $[13,28]$. Recent detection of TC1507-resistant S. frugiperda in Florida and North Carolina [32] may be a result ofthe known migratory behavior of $S$. frugiperda from Puerto Rico through the Caribbean [33]. Consequently, it would be predicted that the same resistance mechanism would be present in S. frugiperda from Puerto Rico and southeastern United States, although this hypothesis has not been testedexperimentally.

\section{Frequency of Resistance Alleles in O. nubilalis Field Populations}

The frequency of Cry $1 F$ a resistant alleles in O. nubilalis has been estimated using $F_{1}$ and $F_{2}$ screens and annual susceptibility monitoring of Midwestern United States populations based on diagnostic and concentration response bioassays [9]. The F2 screen involves collecting a large number of individuals from the field and establishing single-female family lines[34]. The offspring of each collected female are inbred by sibmating and their offspring (i.e., the F2 of the collected generation) are screened with a discriminating concentration for tolerance to the toxin. The $\mathrm{F} 2$ screen allows potentially heterozygous offspring from a field-collected homozygous resistant female to mate with each other, generating 1/4 of homozygous resistant offspring. Through back-calculation of the frequency of family lines containing a resistant allele, the frequency of the resistance alleles in the sampled population can be estimated. The F1 screen involves mating individuals collected from the field with a previously described resistant laboratory strain [10] which is known to be homozygous for resistance.The offspring are tested using discriminating bioassays to distinguish resistant homozygotes from susceptible homozygotes and heterozygotes. Estimates of the frequency of resistance alleles among field populations of $O$. nubilalis indicated that resistance alleles could be detected even during 2003, the first year of Cry1Fa maize commercialization. Resistant allele 
frequencies ranged between 0.029 in 2003-2005 and 0.025 in 2006-2008, indicating no net

increase in frequency. Results from the F2 screenestimated similar frequencies in 2008 and $2009(\approx$ 0.009 and 0.014, respectively), confirming the presence of resistance alleles [9]. Further, the susceptibility of $O$. nubilalis to Cry $1 \mathrm{Fa}$ has been monitored annually using diagnostic and concentration response bioassays since 2003, and these results supported the observations obtained with the $F_{1}$ and $F_{2}$ screens [9]. Taken together, the results from the monitoring and the $F_{1}$ and $F_{2}$ screens suggest that the frequency of Cry1Faresistant alleles in O. nubilalis populations was higher than expected, even prior to the introduction of Cry1Fa maize[9]. Lack of reports of unexpected damage in Bt fields by O. nubilalisis further evidence that the high-dose/refuge strategy is effective in delaying resistance evolution in this pest even when a high frequency of resistance alleles is detected in the field.

\section{Frequency of Resistance Alleles in Field Populations of $S$. frugiperda}

After the first report of S. frugiperda Cry1Fa resistance in Puerto Rico in 2006, populations from both Puerto Rico and the southeastern United States were monitored using different methodologies to detect potential changes in susceptibility. Storer et al. [13] monitored S. frugiperda populations in 2010 and 2011 from Puerto Rico, Texas, Florida, Alabama, and Mississippi using dose range bioassays. In this study, the majority of the collections from Puerto Rico showed high levels of Cry1Fa resistance, whereas populations from southeastern United States exhibited susceptibility similar to the reference laboratory colony [13]. Additional studies evaluated the frequency of Cry1Fa resistance alleles in populations from Puerto Rico (2010 -2013), Florida and Texas (2010 -2011) [16]. The nature of Cry1Fa resistance inheritance in S. frugiperda (i.e., autosomal, recessive and conferred by a single locus) allowed $\mathrm{F}_{1}$ screens using the resistant Puerto Rican population and evaluating the offspring with discriminating bioassays to estimate the frequency of resistance alleles [16]. Using this approach, resistance alleles were detected in both Florida and Texas. In Florida, the frequency of resistance alleles was as high as 0.13 in some populations, with localized differences; while in Texas the frequency was much lower (0.02) but still detectable [16]. These results are consistent with $S$. frugiperda gene flow studies that indicate significant gene exchange between Florida and Puerto Rico and limited gene exchange between Florida and Texas [ $\underline{33}, \underline{35}]$. As stated above, the higher frequency of resistance alleles detected in Florida might be in part the result of migration of resistant individuals from Puerto Rico to Florida. However, local variance 
between Florida counties suggests localized differences in selection pressures [16]. In Puerto Rico, the frequency of Cry $1 \mathrm{Fa}$ resistance remained high between 2010 and 2013, even after withdrawal of TC1507 maize from the local market. This observation may be explained by the resistance allele being fixed in the local populations and/or by the absence of significant fitness costs associated with resistance $[\underline{36}, \underline{37}]$, as further discussed below.

Additional studies using F2 screens with populations from Florida collected in 2011 showed relatively high frequencies of resistant alleles (0.29) [32].In addition, the susceptibility of populations collected between 2012 and 2013 on non-Bt maize from Florida, Louisiana and Georgia, and populations from Bt maize fields with unexpected damage from Florida and North Carolina was assessedwithconcentration response bioassays. Populations from non-Bt maize exhibited 18.8 to $>85$.4-fold resistance to purified Cry1Fa protein, while populations from fields with unexpected damage from Florida and North Carolina showed $>85.4$-fold resistance [32]. The presence of field resistance in south Florida was also evaluated with field trials using Cry $1 \mathrm{Fa}$ and pyramided Bt maize products. Field trials in Florida showed reduced efficacy and control failure of natural $S$. frugiperda populations [32]. The results from $\mathrm{F}_{1}$ and $\mathrm{F}_{2}$ screens suggest that these methods are more sensitive for early detection of resistant alleles [16], while dose range bioassays are generally insensitive to small changes in allele frequencies $[\underline{34}, \underline{38}]$. Overall, these results suggest thatresistance allele frequencies in S. frugiperdawere high prior to the introduction of Cry1Fa maize [16], similar to results with O. nubilalis. However, in contrast to O. nubilalis, the lack of a high dose hindered the ability of the high-dose/refuge strategy to delay resistance in $S$. frugiperda.

\section{Fitness Costs}

Resistance alleles are often assumed to be associated with fitness costs [20], and the relative fitness of heterozygote individuals influences the response to selection and the rate of resistance evolution [39]. The study of fitness costs associated with resistance to Bt insecticidal proteins is fundamental to understanding resistance evolution and the evaluation of resistance management practices implemented to mitigate resistance to transgenic maize in the field [39].

\section{Fitness Costs of Cry1Fa Resistance in O. nubilalis}

The existence of fitness costs in laboratory-selected Cry1Fa resistant $O$. nubilalis wastested by 
comparing life-history traits and population growth parameters in the absence of Cry1Fbetween the resistant strain, a susceptible strain with similar genetic background, and their reciprocal crosses. Comparison of life history traits (i.e. pupal weight, developmental time, growth rate, and number of eggs per female) and population growth parameters indicated weak and recessive fitness costs associated with Cry1Fa resistance [19]. The estimates of relative fitness in that study were obtained under controlled environmental conditions with artificial diet, and suggested that fitness costs associated with resistance are likely to be more apparent when larvae feed on maize plants and under field conditions [40]. Additional experiments were performed to determine if fitness cost of Cry $1 F a$ resistance in $O$. nubilalis would be affected by the presence of host plant resistance by comparing fitness on three maize lines [41]. Two of the maize lines were susceptible to O. nubilalis (F1-hybrid B73xMO17 and WF9) [42] and the third line (B94) expressed moderate levels of the maize benzoxazinoneDIMBOA, which confers resistance against $O$. nubilalis [43]. Larval survival and development were measured in the greenhouse using plants in the vegetative and reproductive stage. Both experiments demonstrated that B94 maize significantly affected survival and developmental rate in both the susceptible and resistant strains indicating no fitness cost of resistance [41] and supporting the results obtained in laboratory experiments[19]. The lack of fitness cost was further confirmed with choice and no-choice experiments on Cry1Fa maize tissue and the respective isoline, where no strong differences were observed between susceptible and Cry1Fa resistant $O$. nubilalis neonates [44].

\section{Fitness Costs of Cry1Fa Resistance in S. frugiperda}

The fitness costs of Cry1Fa resistance in S. frugiperda from Puerto Rico have also been evaluated using susceptible and resistant strains with similar genetic background and their reciprocal crosses $[36,37]$. One study compared life-history traits (i.e. pupal weight, developmental time, growth rate, number of spermatophores per male, and number of eggs/larvae per female) and population growth rate parameters using artificial diet. Results from this study reported no major fitness costs in either heterozygotes or homozygous resistant insects [36]. Additional research compared biological

performance of susceptible and Cry1Fa resistant larvae in artificial diet, in maize or soybean leaf tissue, or in the reproductive tissue of cotton. In this study, researchers measured larval survival, larval and pupal weights, developmental time, adult longevity, fecundity, fertility, and sex ratio [37]. In general, all of the measured parameters were influenced by the host plant but not by the 
strain. The only parameter that significantly differed between the susceptible and resistant strains was the larval developmental time, with resistant larvae exhibiting longer developmental times that resulted in a short asynchrony ( $<2$ days) in peaks of adult emergence between susceptible and resistant strains[37]. Further research compared fitness parameters of two Cry1Fa resistant $S$. frugiperda populations collected from Florida and Puerto Rico with a susceptible strain and the respective reciprocal crosses. Assessed biological parameters included survival, growth and developmental time, and were measured in untreated artificial diet and non-Bt maize leaf tissue [45]. Results from this study showed that the Cry1Fa resistance from Puerto Rico and Florida was associated with a significant fitness cost in all the parameters measured, especially for Florida populations [45]. The discrepancy between this and previous studies may be attributed to different alleles being responsible for resistance among the tested populations or to differences in rearing techniques. To determine the relevance of the negligible fitness costs reported in a resistant strain from Puerto Rico, researchers followed the proportion of homozygous resistant individuals in a heterogeneous strain through 12 generations of rearing on meridic diet, usingdiagnostic Cry1Fa bioassays to determine the percentage of resistant neonate larvae [37]. In a different study, two strains with a fixed resistance allele frequency of 50\% were tested for seven generations of rearing in meridic diet and diagnostic Cry1Fa bioassays were usedto estimate the frequency of resistant alleles in each generation [36]. While the first study found no changes in the proportion of homozygous resistant individuals in the population after 12 generations, the second study found that the frequency of resistance alleles slightly decreased after seven generations in the two lines tested. However, is important to consider that both studies measured different parameters. Jakka et al [37] only reported mortality, underestimating the frequency of resistance alleles since heterozygotes would not be detected. Velez et al. [36] estimated the frequency of resistance alleles, yet it is uncertain if the slight decrease of resistance alleles represented a true fitness cost or was the result of random drift. The consistent levels of resistance in Puerto Rico in the absence of apparent selection $[13,16]$ and the results from measurements of fitness parameters are more consistent with a lack of fitness costs. Additional evidence for the lack of fitness costs of Cry1Fa resistance in $S$. frugiperda from Puerto Rico was provided by choice and no-choice experiments on Cry1Fa maize and the respective isoline. Similar to $O$. nubilalis,no strong behavioral differences were observed between susceptible and Cry1Fa-resistant $S$. frugiperdaneonates, although a small percentage of susceptible larvae abandoned Cry1Fa maize leaf tissue[44]. The lack of strong fitness costs 
associated with Cry1Fa resistance in S. frugiperda is also in agreement with the higher than expected initial resistant allele frequencies in field populations, and suggests that their presence will remain stable in the absence of selection pressure (e.g. Puerto Rico) [ㅎ6].

The fitness costs of Cry1Fa resistance in S. frugiperda from Brazil have also been evaluated with near isogenic susceptible and resistant colonies and their reciprocal crosses [46]. Fitness parameters measured included developmental time, survival rates, sex ratio, adult longevity, timing of oviposition, fecundity, and fertility. The resistant colony showed $7 \%$ lower survival to adulthood and the mean generation time was two days shorter compared to the susceptible colony, yet reproductive parameters were similar between the colonies. Overall, the authors concluded no relevant fitness costs in the Cry1Faresistant colony, indicating, as in the case of populations from Puerto Rico, stability of field resistance to Cry1Fa in S. frugiperda populations from Brazil [46].

\section{Mechanisms of Cry1Fa Resistance}

A complicating factor in our understanding of Cry $1 \mathrm{Fa}$ resistance in both $O$. nubilalis and $S$. frugiperda is that the molecular basis of resistance is still emerging. Such information is critical for understanding the underlying impacts to fitness if any, initial allele frequencies, and ultimately to IRM decisions that are dependent on lack of cross-resistance. Resistance in both species shows a number of similarities, includinglinkage to a single autosomal resistance allele, and absence of relevant fitness costs. However, the lack of Cry1Fa binding to resistant $S$. frugiperda[26] but not to O. nubilalis [18], and the distinct cross-resistance pattern to Cry1A toxins [10,29] support that Cry1Fa resistance genes may differ for the two species. High levels ( $>200$-fold) of resistance to Cry toxins has been most often linked to alterations in the recognition of midgut receptors [47]. Analysis of Cry1Fa binding to brush border membrane vesicles (BBMV) from midgut epithelia of susceptible and Cry $1 \mathrm{Fa}$ resistant strains of $O$. nubilalisdescribed above suggested that reduced binding of Cry1Fawas not associated with resistance[18]. In addition, no differences in activity of luminal gut proteases or altered proteolytic processing of the toxin were observed when comparing susceptible and resistant strains[ㄹ]. Genetic mapping in that Cry1Fa-resistant O. nubilalis strain identified a single quantitative trait locus (QTL) associated with Cry1Fa resistance, which mapped to a single linkage group [49]. Fine mapping positively identified a $46.5 \mathrm{cM}$ QTL region containing the Cry1Fa resistance gene. Within this region, an abcc2-like gene was detected [50]. This detection is relevant becausemutations in $a b c c 2$ geneshave been previously shown to be linked 
with resistance to Cry1 Ac [51-55] and Cry2 Ab [56] in diverse lepidopteran pests. Moreover, there is experimental evidence for $\mathrm{ABCC} 2$ proteins as $\mathrm{Cry} 1 \mathrm{Fa}$ functional receptors in Bombyxmori(L.)[57]. Comparative transcriptome analyses between the Cry1Fa resistant and a near-isogenic susceptible $O$. nubilalisstrain[10] revealed a different scenario involving differential constitutive expression of a number of genes previously associated with the mode of action of Cry toxins, suggesting the involvement of multiple pathways[58]. The resistant strain had higher expression of possible cadherin mutants and lower expression of aminopeptidase $\mathrm{N}$, amylase and alkaline phosphatase genes compared to the susceptible strain. Most of these genes have been identified as Cry toxin receptorsassociated withresistance to Cry toxins in other species [59-63]. Lower expression of v-ATPase and protease activity were also observed in the Cry1Fa resistant strain of $O$. nubilalis,suggesting that altered midgut $\mathrm{pH}$ and reduced protease activity may contribute to Cry1Fa resistance in this insect [58]. Similar observations of the association of gut $\mathrm{pH}$ and altered proteolytic activity have been described in Heliothisvirescens(Fabricius)resistant to Cry1Ac and Cry2A [64] and Aedesaegyptiresistance to B. thuringiensis israelensis(Bti) toxins [60].

Resistance to Cry1Faina S. frugiperda strain from Puerto Rico [26]was associated with reduced expression of selected alkaline phosphatase (ALP) genes that serve as high affinity Cry1Fa toxin-binding sites[65]. Cross-resistance and reduced binding of Cry1 Ab and Cry1Ac but not Cry $1 \mathrm{Ca}$ in this resistant strain identifies the phenotype as Mode 1 resistance [66]. In Plutellaxylostella(L.), Mode 1 resistance involved reduced levels of a toxin binding ALP, as observed for $S$. frugiperda, as well as altered expression of ABCC genes. Both of these processes involved altered expression of a mitogen-activated protein kinase (MAPK) gene[51]. Further work is needed to determine if similar MAPK kinase genes are involved in resistance to CrylFa in $S$. frugiperda. Despite slight differences in genetic transmission and cross-resistance phenotype between S. frugiperda populations from Puerto Rico and Brazil (as described above), resistance in Brazilian strains was also associated with reduced Cry1Fa toxin binding [30].

Continued research to elucidate the causative mechanism and genes of Cry1Fa resistance in both $O$. nubilalis and $S$. frugiperdawill provide crucial information to improve approaches to managing resistance in these two species.

\section{Conclusions}


This paper describes current knowledge on Cry1Fa resistance in two lepidopteran species, $O$. nubilalis and $S$. frugiperda, targeted by Bt maize. Resistance to Cry1Fa in laboratory selected $O$. nubilalis and field resistance in S. frugiperda from Puerto Rico and Brazil has been characterized as recessive, autosomal, monogenic $[\underline{11}, \underline{15}, \underline{16}]$, and not linked to fitness costs $[\underline{19}, \underline{36}, \underline{37}, \underline{46}]$. It remains to be determined if $S$. frugiperda Cry1Fa resistance from Puerto Rico, southern United States, and Brazil are independent resistant events or the results of insect migration [26]. In the case of $O$. nubilalis, resistance has been selected in the laboratory, but field populations remain susceptible even with reports of relatively high frequency of resistant alleles [9]. Taken together, these data supportsuccess of the high-dose/refuge strategy in cases when the assumptions of the model are met, as is the case ofO. nubilalis. However, in cases when at least one of the major assumptions is not met, the likelihood of resistance evolution is higher. This is true in S. frugiperda and other species where the high-dose assumption has not been met [67]. In these cases, the use of pyramided crops expressing toxins with different modes of action and integrated pest management will be fundamental in delaying the evolution of resistance. Cross-resistance [16,23] and binding studies in S. frugiperda[26], suggest that pyramided maize events expressing Cry1Ca and Vip3A should be effective in controlling Cry1F-resistant $S$. frugiperda[16,26]. In contrast, Cry $1 \mathrm{Ab}$ and CrylAcare not suitable for pyramiding with Cry1Fa because of cross-resistance [16,23,29] and evidence for shared binding sites[26]. In conclusion, the lessons learned from Cry1Fa resistance in $O$. nubilalis and $S$. frugiperda highlight the importance of meeting the assumptions of the high-dose/refuge strategy for the successful delay of resistance. Additional pest management strategies will be necessary if the high-dose assumption is not met.

\section{Acknowledgements}

The authors would like to thank Justin McMechan for assisting with the design of the high-dose/refuge strategy diagram. Partial funding for this study was provided by Biotechnology Risk Assessment Grant Program competitive grant No. 2014-33522-22215 from the USDA National Institute of Food and Agriculture.

\section{References}


1. Chambers JA, Jelen A, Gilbert MP, Jany CS, Johnson TB, Gawron-Burke C: Isolation and characterization of a novel insecticidal crystal protein gene from Bacillus thuringiensis subsp. aizawai. J Bacteriol 1991, 173:3966-3976.

2. Adang M, Crickmore N, Jurat-Fuentes JL: Diversity of Bacillus thuringiensis crystal toxins and mechanism of action. In Advances in Insect Physiology Vol. 47: Insect Midgut and Insecticidal Proteins. Edited by Dhadialla TS, Gill S: Academic Press; 2014:39-87.

3. Siebert MW, Babock JM, Nolting S, Santos AC, Adamczyk JJ, Neese PA, King JE, Jenkins JN, McCarty J, Lorenz GM, et al.: Efficacy of Cry1F Insecticidal Protein in Maize and Cotton for Control of Fall Armyworm (Lepidoptera: Noctuidae). Florida Entomologist 2008, 91:555-565.

4. Baktavachalam GB, Delaney B, Fisher TL, Ladics GS, Layton RJ, Locke ME, Schmidt J, Anderson JA, Weber NN, Herman RA, et al.: Transgenic maize event TC1507: Global status of food, feed, and environmental safety. GM Crops Food 2015, 6:80-102.

5. Van Rie J, Ferre J: Insect resistance to Bacillus thuringiensis insecticidal proteins. In Entomopathogenic bacteria: from laboratory to field application. Edited by Charles J-F, Delecluse A, Nielsen-Leroux C: Kluwer Academic Publishers; 2000:219-236.

6. Gould F: Sustainability of transgenic insecticidal cultivars: Integrating pest genetics and ecology. Annu. Rev. Entomol. 1998, 43:701-726.

7. Tabashnik BE, Carriere Y, Dennehy TJ, Morin S, Sisterson MS, Roush RT, Shelton AM, Zhao JZ: Insect resistance to transgenic Bt crops: lessons from the laboratory and field. $J$ Econ Entomol 2003, 96:1031-1038.

8. Bates SL, Zhao JZ, Roush RT, Shelton AM: Insect resistance management in GM crops: past, present and future. Nat Biotechnol 2005, 23:57-62.

9. Siegfried BD, Rangasamy M, Wang H, Spencer T, Haridas CV, Tenhumberg B, Sumerford DV, Storer NP: Estimating the frequency of Cry1F resistance in field populations of the European corn borer (Lepidoptera: Crambidae). Pest Manag Sci 2014, 70:725-733.

** This study demonstrated that $\mathrm{F}_{1}$ and $\mathrm{F}_{2}$ screens were in agreement with annual susceptibility monitoring for Cry1Fa toxin susceptibility in the European corn borer. In addition, results indicated that the high-dose/refuge strategy is effective in delaying Cry1Fa resistance in this insect.

10. Pereira EJG, Lang BA, Storer NP, Siegfried BD: Selection for Cry1F resistance in the European corn borer and cross-resistance to other Cry toxins. Entomologia Experimentalis et Applicata 2008, 126:115-121. 
11. Farias JR, Andow DA, Horikoshi RJ, Sorgatto RJ, Fresia P, dos Santos AC, Omoto C:

Field-evolved resistance to Cry1F maize by Spodoptera frugiperda (Lepidoptera:

Noctuidae) in Brazil. Crop Protection 2014, 64:150-158.

* First evidence that the damage reported in 2011 to Cry 1F maize (TC1507) in Brazil was associated with field evolved resistance to Cry1F in S. frugiperda.

12. Farias JR, Horikoshi RJ, Santos AC, Omoto C: Geographical and Temporal Variability in Susceptibility to Cry1F Toxin From Bacillus thuringiensis in Spodoptera frugiperda (Lepidoptera: Noctuidae) Populations in Brazil. Journal of Economic Entomology 2014, 107:2182-2189.

13. Storer NP, Kubiszak ME, Ed King J, Thompson GD, Santos AC: Status of resistance to Bt maize in Spodoptera frugiperda: lessons from Puerto Rico. J Invertebr Pathol 2012, 110:294-300.

14. Shelton AM, Tang JD, Roush RT, Metz TD, Earle ED: Field tests on managing resistance to Bt-engineered plants. Nat Biotechnol 2000, 18:339-342.

15. Pereira EJG, Storer NP, Siegfried BD: Inheritance of Cry1F resistance in laboratory-selected European corn borer and its survival on transgenic corn expressing the Cry1F toxin. Bulletin of Entomological Research 2008, 98:621-629.

16. Vélez AM, Spencer TA, Alves AP, Moellenbeck D, Meagher RL, Chirakkal H, Siegfried BD: Inheritance of Cry1F resistance, cross-resistance and frequency of resistant alleles in Spodoptera frugiperda (Lepidoptera: Noctuidae). Bulletin of Entomological Research 2013, 103:700-713.

17. Hua G, Masson L, Jurat-Fuentes JL, Schwab G, Adang MJ: Binding analyses of Bacillus thuringiensis Cry delta-endotoxins using brush border membrane vesicles of Ostrinia nubilalis. Applied and Environmental Microbiology 2001, 67:872-879.

18. Pereira EJ, Siqueira HA, Zhuang M, Storer NP, Siegfried BD: Measurements of Cry1F binding and activity of luminal gut proteases in susceptible and Cry1F resistant Ostrinia nubilalis larvae (Lepidoptera: Crambidae). Journal of Invertebrate Pathology 2010, 103:1-7.

19. Pereira EJG, Storer NP, Siegfried BD: Fitness costs of Cry1F resistance in laboratory-selected European corn borer (Lepidoptera: Crambidae). Journal of Applied Entomology 2011, 135:17-24.

20. Gassmann AJ, Carriere Y, Tabashnik BE: Fitness costs of insect resistance to Bacillus thuringiensis. Annual Review of Entomology 2009, 54:147-163.

21. Siebert MW, Tindal KV, Leonard BR, Van Duyn JW, Babcock JM: Evaluation of corn hybrids expressing Cry1F (Herculex (R) I insect protection) against fall armyworm (Lepidoptera 
: Noctuidae) in the southern United States. Journal of Entomological Science 2008, 43:41-51.

22. Buntin GD: Corn Expressing Cry1Ab or Cry1F Endotoxin for Fall Armyworm and Corn Earworm (Lepidoptera: Noctuidae) Management in Field Corn for Grain Production. Florida Entomologist 2008, 91:523-530.

23. Storer NP, Babcock JM, Schlenz M, Meade T, Thompson GD, Bing JW, Huckaba RM: Discovery and characterization of field resistance to Bt maize: Spodoptera frugiperda (Lepidoptera: Noctuidae) in Puerto Rico. J Econ Entomol 2010, 103:1031-1038.

24. Matten SR, Head GP, Quemada HD: How governmental regulation can help or hinder the integration of Bt crops into IPM programs. In Integration of insect-resistant genetically modified crops within IPM programs. Edited by Romeis J, Shelton AM, Kennedy GGS: Springer; 2008:27-39.

25. Blanco CA, Portilla M, Jurat-Fuentes JL, Sanchez JF, Viteri D, Vega-Aquino P, Teran-Vargas AP, Azuara-Dominguez A, Lopez JD, Arias R, et al.: Susceptibility of Isofamilies of Spodoptera frugiperda (Lepidoptera Noctuidae) to Cry1Ac and Cry1Fa Proteins of Bacillus thuringiensis. Southwestern Entomologist 2010, 35:409-415.

26. Jakka SR, Gong L, Hasler J, Banerjee R, Sheets JJ, Narva K, Blanco CA, Jurat-Fuentes JL: Field-evolved Mode 1 resistance of the fall armyworm to transgenic Cry1Fa-expressing corn associated with reduced Cry1Fa toxin binding and midgut alkaline phosphatase expression. Appl Environ Microbiol 2015, 82:1023-1034.

** This study provides a mechanistic description of $S$. frugiperda field-evolved resistance to Cry1Fa. Results support an association between resistance and reduced expression of alkaline phosphatase (ALP) genes that reduce toxin-binding affinity.

27. Santos-Amaya OF, Rodrigues JV, Souza TC, Tavares CS, Campos SO, Guedes RN, Pereira EJ: Resistance to dual-gene Bt maize in Spodoptera frugiperda: selection, inheritance, and cross-resistance to other transgenic events. Sci Rep 2015, 5:18243.

28. Farias JR, Andow DA, Horikoshi RJ, Sorgatto RJ, Santos AC, Omoto C: Dominance of Cry1F resistance in Spodoptera frugiperda (Lepidoptera: Noctuidae) on TC1507 Bt maize in Brazil. Pest Manag Sci 2015.

29. Jakka SR, Knight VR, Jurat-Fuentes JL: Spodoptera frugiperda (J. E. Smith) with field-evolved resistance to Bt maize are susceptible to Bt pesticides. Journal of Invertebrate Pathology 2014, 122:52-54.

30. Monnerat R, Martins E, Macedo C, Queiroz P, Praça L, Soares CM, Moreira H, Grisi I, Silva J, Soberon M, et al.: Evidence of field-evolved resistance of Spodoptera frugiperda to Bt corn 
expressing Cry1F in Brazil that is still sensitive to modified Bt toxins. PLoS One 2015, 10:e0119544.

31. Monnerat R, Martins E, Queiroz P, Ordúz S, Jaramillo G, Benintende G, Cozzi J, Real MD, Martinez-Ramirez A, Rausell C, et al.: Genetic variability of Spodoptera frugiperda Smith (Lepidoptera: Noctuidae) populations from Latin America is associated with variations in susceptibility to Bacillus thuringiensis Cry toxins. Appl. Environ. Microbiol. 2006, 72:7029-7035.

32. Huang F, Qureshi JA, Meagher RL, Reisig DD, Head GP, Andow DA, Ni XZ, Kerns D, Buntin GD, Niu Y, et al.: Cry1F Resistance in Fall Armyworm Spodoptera frugiperda: Single Gene versus Pyramided Bt Maize. Plos One 2014, 9.

* First evidence of field evolved resistance in S. frugiperda to Cry1Fa maize (TC1507) in the United States in Florida and North Carolina.

33. Nagoshi RN, Meagher RL, Jenkins DA: Puerto Rico fall armyworm has only limited interactions with those from Brazil or Texas but could have substantial exchanges with Florida populations. Journal of Economic Entomology 2010, 103:360-367.

34. Andow DA, Alstad DN: F2 screen for rare resistance alleles. Journal of Economic Entomology 1998, 91:572-578.

35. Nagoshi RN, Meagher RL, Hay-Roe M: Inferring the annual migration patterns of fall armyworm (Lepidoptera: Noctuidae) in the United States from mitochondrial haplotypes. Ecol Evol 2012, 2:1458-1467.

36. Vélez AM, Spencer TA, Alves AP, Crespo ALB, Siegfried BD: Fitness costs of Cry1F resistance in fall armyworm, Spodoptera frugiperda. Journal of Applied Entomology 2013, 138:315-325.

37. Jakka SR, Knight VR, Jurat-Fuentes JL: Fitness costs associated with field-evolved resistance to Bt maize in Spodoptera frugiperda (Lepidoptera: Noctuidae). Journal of Economic Entomology 2014, 107:342-351.

38. ffrench-Constant RH, Roush RT: Resistance detection and documentation: The relative roles of pesticidal and biochemical assays. In Pesticide Resistance in Arthropods. Edited by Roush RT, Tabashnik BE: Champan and Hall; 1990:4 - 33.

39. Carriere Y, Ellers-Kirk C, Liu YB, Sims MA, Patin AL, Dennehy TJ, Tabashnik BE: Fitness costs and maternal effects associated with resistance to transgenic cotton in the pink bollworm (Lepidoptera: Gelechiidae). J Econ Entomol 2001, 94:1571-1576. 
40. Raymond B, Sayyed AH, Wright DJ: Genes and environment interact to determine the fitness costs of resistance to Bacillus thuringiensis. Proc Biol Sci 2005, 272:1519-1524.

41. Petzold-Maxwell JL, Siegfried BD, Hellmich RL, Abel CA, Coates BS, Spencer TA, Gassmann AJ: Effect of maize lines on larval fitness costs of Cry1 $\mathrm{F}$ resistance in the European corn borer (Lepidoptera: Crambidae). J Econ Entomol 2014, 107:764-772.

42. Manuwoto S, Scriber JM: Neonate larval survival of European corn borers, Ostrinia nubilalis, on high and low DIMBOA genotypes of maize - Effects of light intensity and degree of insect inbreeding. Agriculture Ecosystems \& Environment 1985, 14:221-236.

43. Abel CA, Berhow MA, Wilson RL, Binder BF, Hibbard BE: Evaluation of conventional resistance to European corn borer (Lepidoptera : Crambidae) and western corn rootworm (Coleoptera : Chrysomelidae) in experimental maize lines developed from a backcross breeding program. Journal of Economic Entomology 2000, 93:1814-1821.

44. Velez AM, Alves AP, Blankenship E, Siegfried BD: Effect of Cry1F maize on the behavior of susceptible and resistant Spodoptera frugiperda and Ostrinia nubilalis. Entomologia Experimentalis Et Applicata 2016.

45. Dangal V, Huang F: Fitness costs of Cry1F resistance in two populations of fall armyworm, Spodoptera frugiperda (J.E. Smith), collected from Puerto Rico and Florida. J Invertebr Pathol 2015, 127:81-86.

46. Horikoshi RJ, Bernardi O, Bernardi D, Okuma DM, Farias JR, Miraldo LL, Amaral FS, Omoto C: Near-Isogenic Cry1F-Resistant Strain of Spodoptera frugiperda (Lepidoptera: Noctuidae) to Investigate Fitness Cost Associated With Resistance in Brazil. $J$ Econ Entomol 2015.

47. Ferré J, Van Rie J: Biochemistry and genetics of insect resistance to Bacillus thuringiensis. Annu. Rev. Entomol. 2002, 47:501-533.

48. Jurat-Fuentes JL, Karumbaiah L, Jakka SR, Ning C, Liu C, Wu K, Jackson J, Gould F, Blanco C, Portilla M, et al.: Reduced levels of membrane-bound alkaline phosphatase are common to lepidopteran strains resistant to Cry toxins from Bacillus thuringiensis. PLoS One 2011, 6:e17606.

49. Coates BS, Sumerford DV, Lopez MD, Wang HC, Fraser LM, Kroemer JA, Spencer T, Kim KS, Abel CA, Hellmich RL, et al.: A single major QTL controls expression of larval Cry1F resistance trait in Ostrinia nubilalis (Lepidoptera: Crambidae) and is independent of midgut receptor genes. Genetica 2011, 139:961-972. 
50. Coates BS, Siegfried BD: Linkage of an ABCC transporter to a single QTL that controls Ostrinia nubilalis larval resistance to the Bacillus thuringiensis Cry1Fa toxin. Insect Biochemistry and Molecular Biology 2015, 63:86-96.

* This study provides further evidence that a region encoding a $a b c c 2$ trasporter is involved in the inheritance of Cry $1 \mathrm{Fa}$ resistance in $O$. nubilalis.

51. Guo Z, Kang S, Chen D, Wu Q, Wang S, Xie W, Zhu X, Baxter SW, Zhou X, Jurat-Fuentes JL, et al.: MAPK signaling pathway alters expression of midgut $A L P$ and $A B C C$ genes and causes resistance to Bacillus thuringiensis Cry1 Ac toxin in diamondback moth. PLOS Genet 2015, 11:e1005124.

52. Baxter SW, Badenes-Perez FR, Morrison A, Vogel H, Crickmore N, Kain W, Wang P, Heckel DG, Jiggins CD: Parallel evolution of Bacillus thuringiensis toxin resistance in Lepidoptera. Genetics 2011, 189:675-679.

53. Gahan LJ, Pauchet Y, Vogel H, Heckel DG: An ABC transporter mutation is correlated with insect resistance to Bacillus thuringiensis Cry1Ac toxin. PLoS Genet 2010, 6:e1001248.

54. Xiao Y, Zhang T, Liu C, Heckel DG, Li X, Tabashnik BE, Wu K: Mis-splicing of the ABCC2 gene linked with Bt toxin resistance in Helicoverpa armigera. Sci Rep 2014, 4:6184.

55. Park Y, Gonzalez-Martinez RM, Navarro-Cerrillo G, Chakroun M, Kim Y, Ziarsolo P, Blanca J, Canizares J, Ferre J, Herrero S: ABCC transporters mediate insect resistance to multiple Bt toxins revealed by bulk segregant analysis. BMC Biol 2014, 12:46.

56. Tay WT, Mahon RJ, Heckel DG, Walsh TK, Downes S, James WJ, Lee SF, Reineke A, Williams $\mathrm{AK}$, Gordon $\mathrm{KH}$ : Insect resistance to Bacillus thuringiensis toxin Cry2Ab is conferred by mutations in an ABC transporter subfamily A protein. PLOS Genet 2015, 11:e1005534.

57. Tanaka S, Miyamoto K, Noda H, Jurat-Fuentes JL, Yoshizawa Y, Endo H, Sato R: The ATP-binding cassette transporter subfamily $\mathrm{C}$ member 2 in Bombyx mori larvae is a functional receptor for Cry toxins from Bacillus thuringiensis. FEBS J 2013, 280:1782-1794.

58. Vellichirammal NN, Wang HC, Eyun SI, Moriyama EN, Coates BS, Miller NJ, Siegfried BD: Transcriptional analysis of susceptible and resistant European corn borer strains and their response to Cry1F protoxin. Bmc Genomics 2015, 16.

** This study compared the global transcriptomic response of Cry1Fa resistant and susceptible $O$. nubilalis strains. Results provide key information on the possible molecular mechanisms in insect response and resistance evolution to Bt toxins. 
59. Morin S, Biggs RW, Sisterson MS, Shriver L, Ellers-Kirk C, Higginson D, Holley D, Gahan LJ, Heckel DG, Carriere Y, et al.: Three cadherin alleles associated with resistance to Bacillus thuringiensis in pink bollworm. Proceedings of the National Academy of Sciences of the United States of America 2003, 100:5004-5009.

60. Despres L, Stalinski R, Tetreau G, Paris M, Bonin A, Navratil V, Reynaud S, David JP: Gene expression patterns and sequence polymorphisms associated with mosquito resistance to Bacillus thuringiensis israelensis toxins. BMC Genomics 2014, 15:926.

61. Knight PJ, Crickmore N, Ellar DJ: The receptor for Bacillus thuringiensis CrylA(c) delta-endotoxin in the brush border membrane of the lepidopteran Manduca sexta is aminopeptidase N. Mol Microbiol 1994, 11:429-436.

62. Sangadala S, Walters FS, English LH, Adang MJ: A Mixture of Manduca sexta Aminopeptidase and Phosphatase Enhances Bacillus thuringiensis Insecticidal Cryia(C) Toxin Binding and (Rb+-K+)-Rb-86 Efflux in-Vitro. Journal of Biological Chemistry 1994, 269:10088-10092.

63. Jurat-Fuentes JL, Adang MJ: Characterization of a Cry1Ac-receptor alkaline phosphatase in susceptible and resistant Heliothis virescens larvae. Eur J Biochem 2004, 271:3127-3135.

64. Karumbaiah L, Oppert B, Jurat-Fuentes JL, Adang MJ: Analysis of midgut proteinases from Bacillus thuringiensis-susceptible and -resistant Heliothis virescens (Lepidoptera: Noctuidae). Comp Biochem Physiol B Biochem Mol Biol 2007, 146:139-146.

65. Oppert B, Kramer KJ, Beeman RW, Johnson D, McGaughey WH: Proteinase-mediated insect resistance to Bacillus thuringiensis toxins. Journal of Biological Chemistry 1997, 272:23473-23476.

66. Tabashnik BE, Liu Y, Malvar T, Heckel DG, Masson L, Ferré J: Insect resistance to Bacillus thuringiensis: uniform or diverse? Philosophical Transactions of the Royal Society of London B Biological Sciences 1998, 353:1751-1756.

67. Tabashnik BE, Van Rensburg JB, Carriere Y: Field-evolved insect resistance to Bt crops: definition, theory, and data. J Econ Entomol 2009, 102:2011-2025. 
Box 1 High-dose refuge strategy used to delay the evolution of resistance in $\mathrm{Bt}$ crops. (1a) Few homozygous resistant insects will emerge from Cry1F maize; (1b) multiple homozygous susceptible insects will emerge from the non-Bt maize refuge; (2) homozygous susceptible insects will mate with homozygous resistant insects; (3) functionally recessive resistance will generate heterozygous offspring that will eventually die with the high-dose expressed in Cry1F maize.

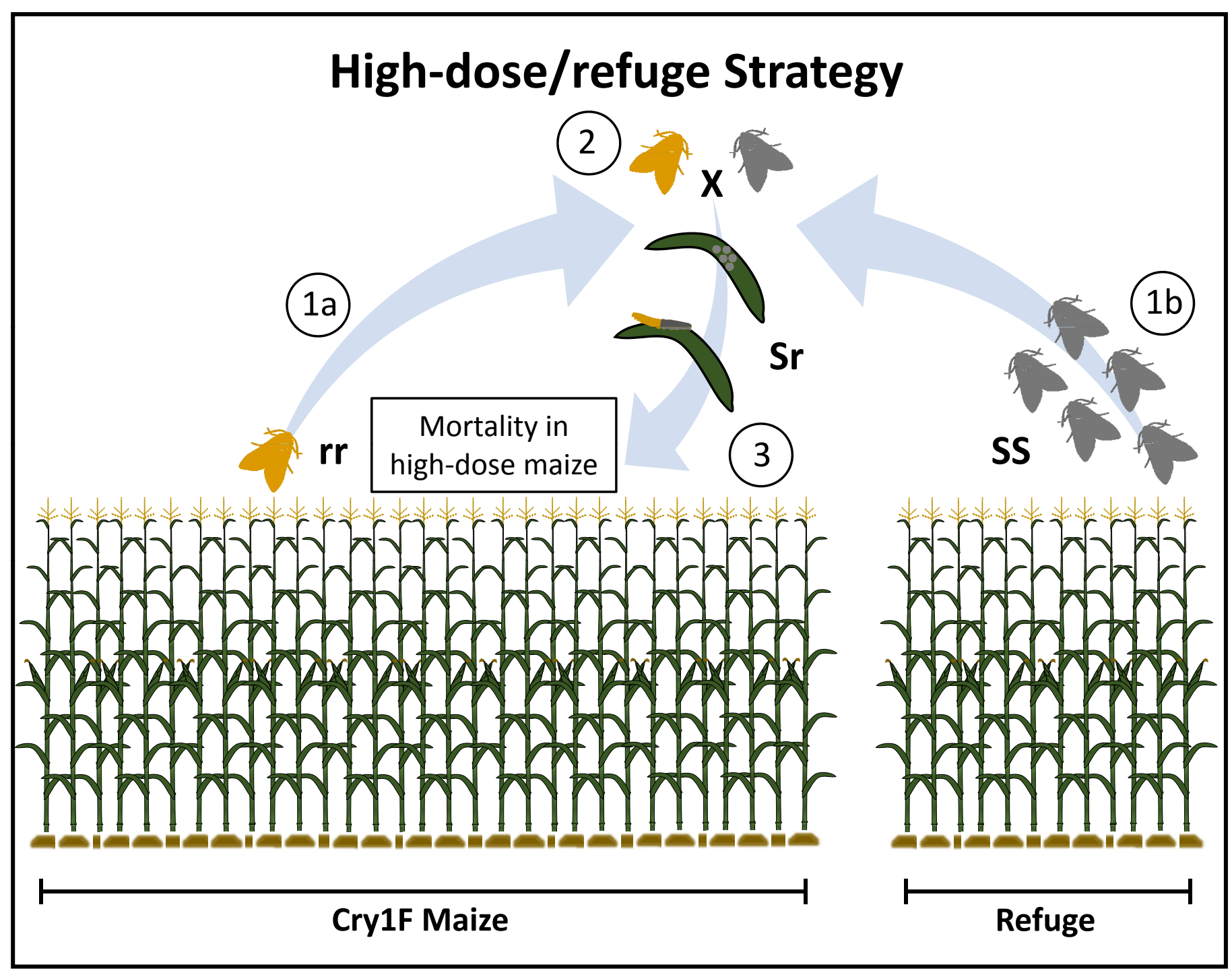

